\title{
CUBA Y LA UNIÓN SOVIÉTICA EN EL MOVIMIENTO DE PAÍSES NO ALINEADOS ${ }^{1}$
}

\author{
Cuba and the Soviet Union in the Non-Aligned Movement \\ Germán Alburquerque* \\ Claudio Coloma**
}

\section{RESUMEN}

El artículo estudia la relación entre Cuba y la Unión Soviética en el marco de la participación cubana en el Movimiento de Países No Alineados. Se demuestra empíricamente -esto es, con documentos de la cancillería cubana- que La Habana y Moscú se coordinaron estrechamente con el fin de favorecer los intereses de ambos Estados dentro del Movimiento. La investigación expone cómo los cubanos asumieron las posturas e ideas soviéticas, así como las recomendaciones y directrices que recibieron de Moscú. Se espera así aportar a la discusión sobre el grado de autonomía que Cuba conservó dentro de su sujeción a la hegemonía soviética.

Palabras clave: Cuba, Unión Soviética, Movimiento de Países No Alineados, Guerra Fría, Tercer Mundo.

\footnotetext{
${ }^{1}$ Este artículo es producto del proyecto FONDECYT de Iniciación en Investigación $\mathrm{N}^{\circ} 11140886$ de la Comisión Nacional de Investigación Científica y Tecnológica, CONICYT-Chile.

* Universidad Bernardo O’Higgins - Centro de Estudios Políticos, Culturales y Sociales de América Latina (EPOCAL). Santiago, Chile. Correo electrónico: german.alburquerque@gmail.com

** Estudiante del Programa de Doctorado en Ideología y Análisis del Discurso de la Universidad de Essex. Essex, United Kingdom. Correo electrónico: claudio_coloma@hotmail.com
}

Artículo recibido el 06 de diciembre de 2017. Aceptado el 20 de marzo de 2018. 


\begin{abstract}
This paper investigates a particular moment in Cuban-Soviet relations: Cuba's participation in the Non-Aligned Movement (NAM). It demonstrates empirically, that is, with documents from the Cuban Ministry of Exterior Relations, that both states coordinated closely along each ones national interests to obtain mutual benefits from their engaging the Movement (NAM). The research shows the way Cuba assumed Soviet positions and ideas, as well as the recommendations and directives it received from Moscow. It is hoped to contribute to the discussion on the degree of autonomy of Havana's foreign policy in relation to the Soviet hegemony.
\end{abstract}

Keywords: Cuba, Soviet Union, Non-Aligned Movement, Cold War, Third World.

\title{
1. Introducción
}

El objetivo de este artículo es develar la estrecha coordinación que existió entre Cuba y la Unión Soviética en lo que concierne a la participación de la primera en el Movimiento de Países No Alineados (MPNA) ${ }^{2}$. Los documentos consultados en el archivo del Ministerio de Relaciones Exteriores de Cuba muestran, además, que los soviéticos controlaron la participación cubana en el Movimiento, lo que da pie para sugerir que el grado de autonomía de Cuba para conducir su política exterior en el marco de la Guerra Fría fue mínimo en todo aquello que se relacionara con el interés soviético. Es sabido que la Cuba revolucionaria se situó bajo la hegemonía de la Unión Soviética y que acorde a esa calidad orientó su política exterior. Sin embargo, hasta ahora los especialistas siempre le han reservado a Cuba una cuota mayor o menor de autonomía. Por nuestra parte pensamos que esa autonomía -es decir, la facultad de un Estado de decidir libre e independientemente su política exterior-1legaba hasta donde empezaban los intereses soviéticos: una vez en contacto con la órbita de la Unión Soviética, Cuba se sometía a su orientación. Luego, la autonomía cubana se habría hallado "en suspenso", inhabilitada o desactivada, por cuanto la presión de la potencia hegemónica estuvo siempre presente.

Esto no quiere decir que Cuba careciera de razones para participar y asumir protagonismo en el Movimiento. Requería ampliar sus vínculos internacionales, en especial por el aislamiento instigado por Estados Unidos; de hecho, en América Latina tenía poquísimos interlocutores. A través del contacto

\footnotetext{
${ }^{2}$ Esta organización, fundada en 1961, aglutinó a los países que no pertenecían a ninguno de los bloques confrontados en la Guerra Fría y que reivindicaban su derecho a la neutralidad.
} 
con los países de África y de Asia, aparte de relaciones diplomáticas, podía encontrar socios comerciales. No debe desconocerse, finalmente, la vocación ideológica de la Revolución y la sed de liderazgo, que encontraban en el MPNA un espacio donde proyectarse.

Como decíamos, los estudios sobre la política exterior cubana han coincidido en subrayar la autonomía que Cuba mantuvo durante la Guerra Fría (Domínguez, 1989; Valenta, 1990; Pettavino, 1990; Riechers, 2012). A finales de los años ochenta, Domínguez enunció la tesis de la autonomía internacional cubana tras constatar que no había evidencia suficiente para demostrar que Cuba había sido un "títere" de la URSS; por el contrario, los antecedentes probaban que el régimen de Fidel Castro gozaba de la suficiente independencia como para desempeñarse en función de sus propios intereses nacionales (Domínguez, 1989, p. 4). Poco tiempo después, Valenta advirtió que en Estados Unidos hubo un malentendido generalizado con respecto a Cuba, pues se la consideró un "actor descontrolado" y un "completo subordinado soviético", en circunstancias que, aunque Cuba debía "acordar con los soviéticos en la mayoría de los temas internacionales, [mantenía] un considerable espacio de autonomía para buscar sus propios objetivos estratégicos, particularmente en África y en la cuenca caribeña" (Valenta, 1990, p. 5). Desde la perspectiva soviética, Roy Allison (1988), a partir de escritos de analistas rusos, ha destacado las coincidencias entre los objetivos soviéticos en el Tercer Mundo y el trabajo cubano en el Movimiento. No obstante, esas coincidencias no se deducen, en su análisis, de una imposición hegemónica soviética, reservándole a Cuba una buena cuota de espontaneidad e iniciativa.

Se han ensayado distintas fórmulas para definir el papel o la condición de Cuba frente a la Unión Soviética. Domínguez (1989) recurre al concepto de hegemonía ajustada ("tight") para graficar que la URSS mantenía una supervisión estricta sobre el comportamiento cubano. Esa hegemonía se caracterizaba por "la coordinación institucionalizada de políticas [...] para proveer beneficios a los dos países, [y por] el consentimiento cubano de no criticar a la URSS públicamente u oponerse a su política exterior" $(62)^{3}$. También se ha calificado a Cuba como aliado, bróker (entre la URSS y el Tercer

\footnotetext{
${ }^{3}$ Este autor, ahondando en el concepto de hegemonía, afirma que "la distribución de poder es tan asimétrica en una relación hegemónica que el estado dominante comúnmente prevalece sobre el estado-cliente en prácticamente todas las áreas [...]. La hegemonía también implica que el estado-cliente tiene algo de autonomía y que el estado dominante restringe su propio comportamiento" (Domínguez, 1989, p. 61).
} 
Mundo) o "intervencionista cooperativo" (Valenta, 1990, pp. 5-7); Estado sustituto (Rubinstein, 1988, p. 168)"; y "proxy" (representante).

¿Cómo han definido los propios cubanos su relación con la URSS? Carlos Rafael Rodríguez, uno de los ideólogos más prominentes de la Revolución, aseguraba que la política internacional cubana era "no solo independiente sino además propia", puntualizando que "aunque Cuba está dispuesta a subordinar siempre sus intereses nacionales a los intereses del socialismo como aspiración universal, ello no significa ni puede significar subordinar nuestra política internacional diaria, con sus objetivos propios y sus propios intereses, a la política de otros estados socialistas" (Rodríguez, 1981, p. 20) 5 .

Sea como fuere, lo cierto es que Cuba, en este periodo, se convirtió en un actor secundario pero relevante de la Guerra Fría, alzándose, probablemente, como el país latinoamericano que más incidió en ese conflicto. En los últimos años los estudios sobre la Guerra Fría han abundado en la consideración de actores que antes fueron confinados a las sombras de la escena principal, en un intento por descentrar las perspectivas tradicionales. Así se ha puesto de relieve la injerencia que tuvieron Estados débiles o de menor tamaño y la forma en que devinieron sujetos de la Guerra Fría y no meros objetos. América Latina por cierto que también se inserta en esta tendencia, discutiéndose si su intervención fue directa o si solo absorbió sus consecuencias y coletazos, si tuvo un rol activo o pasivo.

La cercanía geográfica y una historia de por medio hacían a los países de América Latina aliados naturales de Estados Unidos. La alianza se reforzó con la creación de la OEA y en especial con la firma del Tratado Interamericano de Asistencia Recíproca (1947), un virtual pacto militar que obligaba a los países del continente a ir a la guerra codo a codo con Estados Unidos. Pero los deseos de Washington de asegurarse la concurrencia de los países latinoamericanos chocaron con la realidad, pues cuando en Cuba triunfó la revolución y luego se declaró socialista, iniciando además su amistad con la Unión Soviética, la homogeneidad se quebró. La defección de la isla obligó a los estadounidenses a movilizarse velozmente para que la experiencia no se repitiera. De esa manera la Guerra Fría penetró como nunca antes en el continente, primero a través de la Alianza para el Progreso, que intentó aminorar las condiciones sociales propicias para estallidos revolucionarios, y luego a través de dictaduras militares que inspiradas en la Doctrina de Seguridad Nacional tomaron el mando allí

\footnotetext{
${ }^{4}$ Los sustitutos ("surrogates") eran "usados” para "llenar funciones militares, policiales y económicas, y más importante [...] para mantener en el poder a líderes pro-soviéticos” (Rubinstein, 1988, p. 168).

${ }^{5}$ Consignemos que la misma Constitución cubana del año 1976 reconocía formalmente el lazo con la Unión Soviética (D’Estefano Pisani, 2002, p. 263).
} 
donde la agitación política hacía probable la irrupción de gobiernos refractarios a los dictados norteamericanos.

A juzgar por los esfuerzos de EE. UU. queda claro que América Latina representaba parte importante de lo que consideraba su base de apoyo y que no estaba dispuesto a sacrificarla. Tanto es así que la Guerra Fría en el continente adoptó una dinámica propia, vale decir autónoma de lo que estaba sucediendo a nivel general. En los años sesenta y sobre todo después de la Revolución Cubana se atestiguó en la región una influencia directa y una presencia muy tangible de Estados Unidos, lo que puede relacionarse con un recrudecimiento de la pugna Este-Oeste. Sin embargo, en los años setenta la Guerra Fría entró en una fase de distensión que no supuso un relajamiento en esta parte del mundo. Aquí las cosas siguieron igual o peor que antes, como lo prueba el Golpe de Estado contra Salvador Allende en Chile, los golpes en Argentina y Uruguay, y el endurecimiento del gobierno militar brasileño. Al finalizar la década, la reacción contra la revolución sandinista en Nicaragua por parte de Estados Unidos, esta vez sí respondió al resurgimiento de la Guerra Fría gatillado por el gobierno entrante de Ronald Reagan ${ }^{6}$.

Lo anterior refleja que los países de América Latina y el Caribe, al tiempo que fueron condicionados en su curso histórico por la Guerra Fría, le aportaron su propia complejidad y le imprimieron una vida particular, tal como se expresa en este trabajo a través de las peculiaridades de la Cuba revolucionaria. Con todo, entender la situación de Cuba en el No Alineamiento no puede perder de vista el marco general donde se insertaba. Tanto la urgencia con que Cuba quería responder al bloqueo estadounidense por medios diplomáticos, así como el interés con que los soviéticos articulaban su política con la cubana, respondían al juego de poder a escala global en el que todos estos actores -las superpotencias, Cuba y el Movimiento de Países No Alineados- participaban.

La exposición se dividirá en tres niveles y en función de tres categorías distintas de documentos. El primer nivel, el más superficial, corresponde a los documentos oficiales y públicos de la cancillería cubana; el segundo nivel emana de documentos oficiales de circulación interna o circunscrita a la cancillería cubana pero también a otros ministerios y al Partido Comunista cubano; el tercer nivel indaga en documentos privados y a menudo secretos que dan cuenta del trabajo coordinado entre Cuba y la Unión Soviética frente al Movimiento de Países No Alineados.

\footnotetext{
${ }^{6}$ Tanya Harmer ha identificado una "Guerra Fría interamericana": "Más que una lucha bipolar entre superpotencias proyectada dentro del teatro latinoamericano desde fuera, esta Guerra Fría interamericana fue una disputa única y polifacética entre partidarios regionales del comunismo y del capitalismo, aunque en formas variadas" (Harmer, 2013, pp. 8-19).
} 


\section{La voz oficial}

Durante los años sesenta, con ocasión de las dos primeras reuniones oficiales del Movimiento, los cubanos se contentaron con expresar argumentos moderados que no adoptaron mayor compromiso y que, ciertamente, no aludían a la Unión Soviética con nitidez. Esta etapa se caracterizó para la isla por cierta indiferencia.

En los setenta Cuba giró de modo radical su política hacia el No Alineamiento ${ }^{7}$. Lo mismo ocurrió con la Unión Soviética frente al Tercer Mundo en general. ¿Fue simple coincidencia? Creemos que no, que lo primero fue, en parte, consecuencia de lo segundo. De hecho, Cuba no solo incrementó su interés en el MPNA, sino que también agregó a la Unión Soviética y al bloque socialista explícitamente a su discurso.

Ya en Lusaka, Zambia (1970), los cubanos hicieron la distinción entre el imperialismo estadounidense y la solidaridad que la Unión Soviética dispensaba a los pueblos desfavorecidos. Es llamativo que no se nombrara a la Unión Soviética con todas sus letras, sino que se utilizara el rótulo de "países socialistas": "no confundamos bajo el falaz rubro de grandes o ricos a los países socialistas desarrollados con los países capitalistas desarrollados. El sostén más sólido y la fuerza más pugnaz del frente antimperialista lo constituyen justamente los países socialistas" ("Discurso del Dr. Raúl Roa”, 1970, p. 3 ).

El grado de compromiso, a nivel discursivo, fue intensificándose a medida que avanzaba la década. Un primer avance significativo se observó en la Conferencia Preparatoria de Guyana dos años después, cuando el canciller Raúl Roa nombró con todas sus letras, usando los mismos adjetivos, a la potencia: "Los países socialistas, con la Unión Soviética a la vanguardia, constituyen el cimiento más sólido y la fuerza más pugnaz del frente antimperialista mundial" ("Discurso del Dr. Raúl Roa", 1973, p. 17).

Pero fue en la IV Conferencia del MPNA, en Argel el año 1973, que el propio Fidel Castro, asistiendo por primera vez a una cumbre, anunció la tesis de la alianza natural entre el Tercer Mundo -el del No Alineamiento- y la Unión Soviética. Esto le venía al dedillo a Moscú. Los soviéticos habían entendido que debían variar su política hacia el Tercer Mundo a consecuencia del enfrentamiento cada vez más crispado con los chinos, quienes le disputaban,

\footnotetext{
${ }^{7}$ Hasta los sesenta, la apuesta cubana de internacionalización hacia el Tercer Mundo había radicado en la "tricontinentalidad". De hecho, la Conferencia Tricontinental de La Habana, el año 1966, dio origen a la Organización de Solidaridad de los Pueblos de África, Asia y América Latina, OSPAAAL, que congregaba tanto a países como a agrupaciones políticas.
} 
con éxito, la calidad de líder internacional de la revolución socialista (Friedman, 2015). Moscú quiso adquirir o recuperar el apoyo de las naciones africanas y asiáticas, y también de las latinoamericanas a partir de la revolución cubana; así la atención que prestaba al Movimiento de Países No Alineados fue creciendo desde fines de los sesenta, y en ese juego Cuba podía ser de gran ayuda para acercar al Tercer Mundo con el Segundo. En el tránsito de una década a otra, por lo tanto, se sucedieron fenómenos que confluyeron en un solo resultado: por una parte, los soviéticos decidieron disputarle el Tercer Mundo a Beijing; por otra, los cubanos se vieron en la obligación de cobijarse bajo el paraguas económico de la URSS. Por la misma época, la Primavera de Praga fue truncada por la intervención del Pacto de Varsovia; los cubanos, ante la sorpresa de muchos, dieron su aprobación: el pacto ya estaba firmado. El año 1970, en la Conferencia No Alineada de Lusaka, los cubanos participaron con una motivación diferente a la mostrada en Belgrado y El Cairo, luciendo su deseo de adquirir protagonismo en el Movimiento; en la cumbre de 1973 todo finalizaba con el encendido discurso de Castro: los No Alineados y el bloque socialista son hermanos indisociables ${ }^{8}$. Como corolario, la tesis de los dos imperialismos, según la cual ambas superpotencias se comportaban como imperios, era duramente cuestionada:

¿Cómo se puede calificar de imperialista a la Unión Soviética? ¿Dónde están sus empresas monopolistas? [...] ¿Qué obrero es explotado en algún país de Asia, África o América Latina, por el capital soviético? [...] Todo intento de enfrentar a los países No Alineados con el campo socialista, es profundamente contrarrevolucionario y beneficia única y exclusivamente a los intereses imperialistas (Castro, 1973, p. 4).

En Colombo, durante la cumbre de 1976, Cuba expuso no solo los principios que solventaban la alianza, sino los hechos que la avalaban. Aludiendo a la intervención cubana en Angola, exaltó la ayuda material soviética que permitió el triunfo del MPLA (Movimiento Popular de Liberación de Angola), prueba de la eficacia de la colaboración entre el movimiento de liberación y el bloque socialista.

En Colombo se definió como sede de la próxima cumbre a Cuba, lo que representó el cénit de la participación cubana en el MPNA. Después de quince años como miembro llegaba la hora del liderazgo. Cabe considerar que

\footnotetext{
${ }^{8}$ Otro hito en la alianza Cuba-URSS fue la Declaración de La Habana, de 1974, donde se explicitaba la cooperación entre ambos Estados.
} 
albergar la reunión implicaba varios privilegios, como preparar los documentos a discutir, ejercer fuerte influencia en la invitación a países y movimientos y, una vez celebrada la conferencia, asumir la presidencia del grupo. Como presidente comandaba la redacción de resoluciones, organizaba las reuniones ministeriales o preparativas, oficiaba como árbitro en conflictos entre miembros, etc.

Pero Cuba no llegaba sola a la testera del Movimiento, lo hacía también, en las sombras, la Unión Soviética, algo que no pasó inadvertido a los otros países miembros, al punto de tensionar el devenir interno de la organización de modo inédito. Se objetaba la calidad no alineada de la isla, en atención a su indisimulada alianza con Moscú (Latrèche, 2011, p. 134). En el discurso de inauguración Fidel Castro no rehuyó las dudas suscitadas:

¿Que mantenemos relaciones fraternales con la comunidad socialista y la Unión Soviética? Sí, somos amigos de la Unión Soviética (aplausos). Estamos profundamente agradecidos al pueblo soviético, porque su colaboración generosa nos ayudó a sobrevivir y a vencer en momentos muy difíciles y decisivos de la vida de nuestro pueblo, cuando incluso corríamos peligro de ser exterminados ("Discurso pronunciado", 1979, para. 14).

De esta manera Cuba transparentaba una amistad que según sus criterios debía ser emulada por el resto de los países periféricos, al tiempo que validaba sin ningún miramiento la alianza natural entre los No Alineados y el bloque socialista. Lo que empezó con tibias alusiones a los países socialistas a inicios de la década, terminaba con el reconocimiento expreso de la URSS como aliado, incluso como patrocinador, hacia 1979.

Lamentablemente para el flamante país líder del Movimiento, pronto estallaron los sucesos de Afganistán, que pusieron a la Unión Soviética en el ojo del huracán. La invasión a Afganistán, en defensa del gobierno socialista local, fue considerada de inmediato por la comunidad internacional como una intromisión inadmisible que transgredía uno de los mayores principios del No Alineamiento, el de la no intervención. Cuba debió lidiar con una situación límite que le exigía un ejercicio de equilibrismo. Cuando terminó la presidencia cubana del MPNA, con la celebración de la Conferencia de Nueva Delhi en 1983, el mismo Fidel Castro asumió las responsabilidades:

Buscábamos estos objetivos con independencia de las simpatías y la solidaridad de Cuba hacia la Revolución Afgana, que no hemos dejado de expresar y no hemos ocultado nunca. No obtuvimos el éxito necesario. Por ello, cuando surgen los acontecimientos relacionados con las tropas soviéticas en Afganistán, decidimos continuar el camino emprendido anteriormente en 
busca de una salida honrosa y aceptable para todas las partes involucradas en la compleja situación creada (Castro, 1983, p. 5).

La sola mención de "tropas soviéticas" era impensable hacia 1980; ahora, cuando se dejaba la presidencia, era más sencillo llamar las cosas por su nombre.

\section{La voz restringida}

A partir de la participación en Belgrado (1961), los cubanos fueron adentrándose en la dinámica del Movimiento de modo paulatino, tanteando el terreno, exhibiendo una permanente preocupación por los efectos - positivos y negativos- que el No Alineamiento podía causar a la Unión Soviética, aunque sin perder de vista los propios objetivos. Por otra parte, en La Habana existía el cuidado de no contradecir el discurso oficial soviético, llegando a adoptar algunos de sus conceptos básicos, así como amigos y enemigos.

Ya hacia fines de los sesenta era ostensible una posición de mayor compromiso con la URSS, aun cuando Cuba no tenía todavía mayores pretensiones en el MPNA. Ante la disyuntiva de solo asistir o de figurar en la conferencia de Lusaka, se sopesaba el grado de cercanía con los soviéticos: "Nuestro Primer Ministro [...] señaló que en nuestra perspectiva internacional no está precisamente la de romper los vínculos con la URSS de tipo militar, subrayando por el contrario nuestra disposición a, si es posible, establecer más vínculos de tipo militar". Ello redundaría en una "posición más definida frente a la no alineación, movimiento que ha tratado de ser utilizado en más de una ocasión para enfrentarlo a la URSS" (Documento sin título $\mathrm{N}^{\circ} 1$, c.1970, 1415). Se denota la temprana conciencia cubana de que mientras mayor fuera el lazo con Moscú, mayor sería el rol jugado en el Movimiento, al tiempo que se descartaba tomar distancia de los soviéticos si ello era requisito para permanecer en el organismo.

De cualquier forma, los cubanos ya trabajaban en sintonía con la URSS en el Movimiento. Antes de la Conferencia de Lusaka formulaban como una de sus metas, y a propósito de la invasión del Pacto de Varsovia a Checoslovaquia, "rechazar de modo categórico cualquier intento de usar la Conferencia como tribuna antisoviética" ("Problemas focales", 1970, p. 4); misión que en apariencia fue exitosa, porque al hacer el balance de la actuación en Zambia se destacaba que gracias a la delegación cubana se suprimió en la Declaración Final "el veneno antisoviético más evidente" ("III Conferencia", 1970, p. $3)$. Se concluía tras la reunión que "se han fortalecido las relaciones con la URSS" ("III Conferencia", 1970, p. 6), y se felicitaban de que la Conferencia 
tuviera "un marcado sello político y antimperialista, rescatándola de las pretendidas aspiraciones tendientes a formalizar la existencia de un Tercer bloque, enfrentado fundamentalmente al campo socialista" (Comisión de Altos Estudios Políticos, c.1970, p. 9). Y luego de Lusaka, con miras a una reunión preparatoria, se podía ver con claridad la raíz prosoviética del impulso cubano al resolver "apoyar las iniciativas de la URSS sobre la Conferencia Mundial de Desarme y el Fortalecimiento de la Seguridad Internacional" ("Actividades preparatorias", 1971, p. 4). Los objetivos ajenos pasaban ahora a ser propios.

Avanzada la década la alianza se fortalecía y cada vez más los términos en que los cubanos se expresaban aludían con mayor transparencia a la comunidad de intereses y objetivos existente entre Cuba, los No Alineados, el campo socialista y la URSS. La iniciativa de convertir el océano Índico en una zona de paz o desmilitarizada fue un tema polémico que los cubanos no querían dejar pasar: "El resto de los países socialistas, y especialmente la URSS, considera necesario que se incluya". Estimaban que los países subdesarrollados se concentraban en los problemas económicos y en los asuntos coloniales, despolitizando la ONU. Por lo tanto, "en el proyecto de Declaración que presenta Cuba incluimos la distensión en un marco que consideramos aceptable: la necesidad de su fortalecimiento y extensión, objetivo común en la lucha por la paz y la seguridad internacionales" ("Buró Político", 1975, p. 7).

Lo anterior condensa el concepto que los soviéticos querían instalar -la distensión- y la acción que los cubanos decidían emprender -incluirlo en la declaración-; así, la conducta cubana aparece fundada en la singular visión soviética de la política internacional. Algo similar ocurrió con la moción de reformar la carta de Naciones Unidas con la intención de hacerla más democrática, a lo cual "la Unión Soviética y los países socialistas nos oponemos" (Documento sin título $\mathrm{N}^{\circ} 2,1976$, p. 8). La misma actitud afloraba en uno de los propósitos que Cuba se fijaba antes de una conferencia:

Nos opondremos... a que se adopten medidas que limiten o impidan facilidades de navegación, sobrevuelo o logísticas para las fuerzas de la Unión Soviética, que como ha quedado demostrado en Angola y otras regiones, están al servicio de la paz, la lucha antimperialista, anticolonialista y antineocolonialista (Documento sin título $\mathrm{N}^{\circ} 2,1976$, p. 19).

Con el ascenso de Cuba a la presidencia del Movimiento, el año 1979, se intensificó el esfuerzo por consolidar la alianza de ambos mundos y por resguardar la imagen de la URSS. De modo explícito planteaban como una tarea a ejecutar durante el ejercicio de la presidencia "incrementar y sistematizar la colaboración y el intercambio de información con la URSS y los 
países socialistas hermanos...en relación con el Movimiento" ("Balance de la situación", c.1983, p. 16). Incluso se proponían, con toda franqueza, "impedir que la URSS sea condenada en el seno del MNOAL y evitar que este tema sea inscrito en sus próximas reuniones" ("Balance de la situación", c.1983, p. 21). La frase anterior nos introduce en el gran dolor de cabeza del bloque socialista hacia esos años: Afganistán.

Es sabido que la invasión soviética tensionó al No Alineamiento y sobre todo a Cuba por encontrarse esta en la presidencia del MPNA, una cruel coincidencia que le costó incluso el ingreso al Consejo de Seguridad de Naciones Unidas debido al deterioro de su imagen hasta entonces de independencia (relativa). No haber censurado la intervención exacerbó su grado de compromiso con Moscú. Desde que el hecho estalló, Cuba caminó sobre un precario equilibrio: por un lado debía cumplir uno de los objetivos centrales de su misión en el Movimiento, proteger a la URSS, por otro debía guardar lealtad al No Alineamiento como principio y al simple hecho de presidir la organización, que le obligaba a representar a la totalidad de los Estados miembros.

En la reunión plenaria en Naciones Unidas de 1980 (donde se reunían los delegados de los Países No Alineados) el conflicto amenazó la continuidad del organismo:

La tarea fundamental de la Presidencia cubana es lograr que el Movimiento salga de su actual estancamiento en Nueva York y pueda examinar otros temas que por su interés para un importante número de países, nos puede facilitar la adopción de alianzas temporales que contribuyan al objetivo principal de condenar la actual política de la Administración de Carter y salir del escollo creado por la consideración de los sucesos de Afganistán ("Pro memoria", 1980, p. 1).

Al analizar la correlación de fuerzas presentes en esa ciudad norteamericana los cubanos calculaban que once países compartían su posición, consistente en evitar "tratar el asunto como una injerencia" y en condenar "todas las acciones de la escalada militar del imperialismo en el mundo" ("Evaluación resumida", 1980, p. 2). En estos términos definían Cuba, Vietnam, Afganistán, Angola, Granada y la OLP, entre otros, la aguda contingencia, exculpando a los soviéticos y recusando al enemigo omnipresente.

Para la elaboración de las resoluciones de una próxima conferencia, los cubanos tenían claro que debían "evitar la mención a las tropas soviéticas en el contexto de la declaración", aunque se confesaban "conscientes que la solicitud de la 'retirada de las tropas extranjeras de Afganistán' es un requisito 
insoslayable en cualquier formulación que se presente", sintiéndose obligados a manifestar "apoyo explícito y respeto a la independencia, integridad territorial y seguridad de Afganistán”, y a "condenar todo tipo de intervención e injerencia desde el exterior" ("Proyecto de directivas", c.1980, p. 2). Era una delicada manera de dejar satisfechos a todos, reconociendo, sí, que cualquier fórmula tenía su costo.

Al parecer el gobierno de Castro, transido por tamaña aflicción, recurrió a la propia Unión Soviética para salir del atolladero. Con posterioridad a la conferencia cumbre de Nueva Delhi, y haciendo un balance de aquellos días, los cubanos expresaron:

Hicimos además coordinaciones, pensamos que más amplias que nunca antes con los compañeros soviéticos en el interés de que la Unión Soviética contribuyera a neutralizar las presiones que se estaban ejerciendo sobre la India y sobre Paquistán con relación al tema de Afganistán, al que concedíamos una especial importancia (Documento sin título N³, 1983, p. 6).

Los documentos restringidos del Ministerio de Relaciones Exteriores de Cuba reflejan la toma de conciencia del gobierno de que su política exterior ya no podía seguir siendo concebida en meros términos individuales sino que debía responder al bloque del que formaba parte. Asoma el convencimiento de que la misión en los No Alineados implicaba de forma directa favorecer los intereses de la Unión Soviética ya que habría carecido de sentido haber tomado las riendas del Movimiento solo para satisfacer las necesidades nacionales, que por cierto existieron y fueron fundamentales también.

\section{Las voces secretas}

Por último, analizamos aquellos documentos reservados a las autoridades de la cancillería y del gobierno de Cuba que iluminan el proceso de toma de decisiones y la injerencia en este de la Unión Soviética. Son documentos que expresan la voz oficial cubana pero también la voz de los propios soviéticos, aunque mediatizada - a veces traducida- por la cancillería de la isla.

Solo hacia finales de la década del sesenta encontramos documentos que registran un diálogo o intercambio entre ambos países en lo que respecta al No Alineamiento, más precisamente con vistas a la Conferencia Cumbre de Jefes de Estado de Lusaka, Zambia, en 1970. Esta tercera conferencia reanudaba tras seis años los encuentros del Movimiento (no se realizó la Conferencia programada para el año 1967). En Dar es-Salaam, Tanzania, se celebró la reunión preparatoria de aquella de Lusaka. De poco antes data el siguiente documento, 
una comunicación de Moscú a La Habana, con la anotación "Traducción no oficial” (del ruso al español), que decía: "Es muy importante que se mantenga y profundice la orientación antimperialista y anticolonialista del movimiento de no alineación, que éste participe cada vez más activamente en la lucha contra las maniobras del imperialismo" (Documento sin título $\mathrm{N}^{\circ} 4$, c.1969, p. 1). Ya sabemos entonces que el Movimiento era relevante para los soviéticos y que incluso podía representar una ayuda en su lucha contra Estados Unidos, lo cual reflejaba el cambio en su política hacia el Tercer Mundo. Sin embargo, lo más interesante venía a continuación:

Nos parece que antes de resolver definitivamente el problema de participación de Cuba en esta reunión, sería útil procurar aclarar en forma más detallada los asuntos que se propone incluir en su agenda y las disposiciones de los más activos participantes de la futura reunión, en cuanto al carácter de sus resoluciones. Tales son las consideraciones que nosotros en el momento presente estimamos conveniente expresar a los amigos cubanos en relación con su mensaje (Documento sin título $\mathrm{N}^{\circ} 4$, c.1969, p. 2).

Al margen de cierto desconocimiento soviético acerca del MPNA que expresa su, hasta ese entonces, escaso interés, el texto habla de un "mensaje" cubano que, según se puede deducir, consultaba a Moscú qué camino seguir o qué actitud tomar en la organización. No hemos dado con el mensaje original, pero la sola alusión a él nos resulta decisiva para entender que Cuba no tenía una convicción formada con anterioridad, basada en criterios exclusivos de su política exterior. Al parecer la decisión quedó diferida para el momento en que tanto soviéticos como cubanos tuvieran mayor información, lo que sucedió después de Dar es-Salaam y antes de Lusaka...

Conocemos, gracias a una traducción no oficial realizada por la cancillería cubana, un comunicado de Moscú a sus embajadores apostados en países miembros del MPNA -“entrevístese con el Jefe de Estado (o de Gobierno), con el Ministro de Relaciones Exteriores y [sus] funcionarios responsables [...] así como con la dirección de los amigos [PCs locales, suponemos]"- en el que se les instruía acerca de la III Conferencia de Jefes de Estado de Lusaka, y que revela una toma de posición ya más definida por parte del Kremlin. Por supuesto, el embajador en La Habana también recibió las recomendaciones, que partían por ponderar la afinidad soviética hacia los países tercermundistas, fundada en similares intereses por la paz y la cooperación en el escenario internacional. Preocupación existía en la URSS, según el documento, por la oposición que tensionaba a los No Alineados entre aquellos países que optaban por la "conservación y el desarrollo ulterior de 
los fundamentos antimperialistas y anticoloniales de la no alineación”, y aquellos que "quisieran desviar la próxima conferencia de la condenación de las acciones agresivas del imperialismo" (Documento sin título, N5, c.1970, p. 2). La Unión Soviética, en ese marco, recordaba su "ayuda multifacética" y apoyo a los países en desarrollo y a los movimientos de liberación nacional, refrendando así la pretendida unidad entre Segundo y Tercer Mundo y despejando las dudas acerca del interés soviético en el Movimiento. Terminaba el mensaje con un enérgico llamado a los participantes del Movimiento para que intervinieran en Lusaka:

Exprese la esperanza de que [el] Gobierno del país en que está acreditado [...] valiéndose de su autoridad entre los países no alineados, hará un aporte positivo al trabajo de la próxima conferencia de los países no alineados en interés del fortalecimiento de la seguridad internacional y de la colaboración pacífica de los pueblos (Documento sin título, N5, c.1970, p. 6).

Los soviéticos habían decidido considerar el Movimiento como una instancia relevante que era preciso manejar o al menos influenciar. Un informe remitido por el embajador cubano en Yugoslavia daba cuenta de la postura soviética:

La URSS estima que considerarían positiva la Conferencia si ésta muestra tendencias a mantener los principios de Belgrado y El Cairo. Pero subrayan que en los últimos tiempos, Yugoslavia y otros países bajo su influencia tratan de formular un nuevo concepto de la no alineación en el sentido de enfrentarla a los bloques encabezados por la URSS y los Estados Unidos, lo que juzgan inadmisible (“Informe sobre”, c.1969, p. 15).

El cubano manifestaba que su par soviético tenía conciencia del rol de Yugoslavia y de su arrastre al interior del MPNA, pero también la esperanza de que contrarrestaran esa tendencia los países amigos, vale decir "Argelia, Siria, Sudán, Libia y Cuba, si por fin asiste" ("Informe sobre", c.1969, p. 15). Esto último es esencial, porque marca la todavía tibia postura de Cuba, cuya sola asistencia a Lusaka estaba en duda, y porque puede interpretarse como una sugerencia a que Cuba no solo se hiciera presente, sino que además bregara en favor de los intereses soviéticos y de ese modo emulase los esfuerzos que otros países de la órbita socialista o afines a la URSS harían.

Años más tarde, con la V Conferencia de Colombo en perspectiva, observamos un tono más atildado y consciente respecto al No Alineamiento que dejaba atrás las dudas y avanzaba hacia un control más estricto de la organización. El delegado cubano en Naciones Unidas informaba de un 
encuentro con el embajador soviético en el que este le hizo entrega de las propuestas de declaración para la próxima conferencia. Luego el embajador expresó su "preocupación" ante una serie de tópicos que podían afectar a la URSS. Acusaba poco interés de los países del Tercer Mundo por el desarme y la distensión; recelaba de la revisión de la Carta de la ONU, que conduciría a una confrontación entre la URSS y el Tercer Mundo; alertaba sobre la posible influencia china en el Movimiento. Los representantes acordaron una reunión de expertos de ambos países "para examinar los posibles textos y sus variantes" (Comunicación dirigida [1], 1975) y así aplacar los resquemores soviéticos, algo no tan sencillo si atendemos a que pocos días después el cubano comunicaba:

los compañeros de la URSS están interesados en conocer por qué la agenda no contiene punto ampliado sobre el desarme y los problemas planteados alrededor de la zona de paz del Índico. Se explicó primero la característica de la reunión y las tendencias en los No Alineados y luego la necesidad de elaborar conjuntamente Cuba-URSS la formulación sobre el Índico que sea aceptable para la URSS y los No Alineados. Se convino en que volverían a reunirse próximamente con este propósito (Comunicación dirigida [2], 1975).

Entrelíneas apreciamos cierto reproche soviético al cual los isleños intentaban responder, sugiriendo una redacción en equipo de los párrafos en cuestión. Así se documenta la estrecha colaboración entre ambos Estados, que en la formulación de un texto buscaban satisfacer tanto a la URSS como a los No Alineados, y donde Cuba ejercía de puente entre unos y otros, un papel que el encargado de negocios soviético en La Habana, poco después, reconocería:

Estamos reconocidos a los compañeros cubanos por el esfuerzo que ellos aplican, con tal de que decisiones de la próxima Conferencia en Colombo sean de carácter antiimperialista y contribuyan al desarrollo y la comprensión entre los estados socialistas y los países no alineados (Transcripción de entrevista, 1976, p. 1).

En poco tiempo, entre 1969 y 1976, el Movimiento de Países No Alineados había pasado a ser una instancia importante para la URSS, al punto que se trazaba la meta de ejercer la influencia en la orientación política de la siguiente cumbre, para lo cual contaban con Cuba.

Años más tarde los papeles, desde cierto punto de vista, se invirtieron. Ahora eran los soviéticos los que actuaban en favor de la isla. Por una parte, sucedió que Pakistán intentó organizar una cumbre de países del Tercer Mundo con la aparente voluntad de eclipsar la VI Conferencia de los No Alineados, a celebrarse en La Habana. El encargado de negocios soviético en Cuba, al 
respecto, tranquilizaba a sus aliados comunicándole al vicecanciller Anillo que la URSS había "instruido a sus Misiones en Argelia, India, Guinea, Irak, Somalia, Angola, Mozambique, Madagascar, Mali, Etiopía y Nigeria para que se mantengan atentos a esta maniobra de Pakistán y le ofrezcan toda resistencia posible" ("Resumen de las informaciones", c.1978). Por otra parte, con motivo de la invasión a Afganistán, los cubanos solicitaron determinados gestos a los soviéticos. Durante la ya mencionada reunión en Nueva York y con la intención de destrabar los acuerdos, para los cubanos "el primer paso para proceder a la conclusión de dicha Reunión Plenaria, obligatoriamente, es la información que es necesario brindarle a la URSS para que conozca que es necesario adoptar el consenso que objetivamente exista en relación con Afganistán" ("Propuestas para concluir", 1980, p. 1). Lo que pedían era que Moscú se resignara a una declaración, si bien no del todo su gusto, al menos moderada, para que Cuba pudiera brindar continuidad al Movimiento e inhibir reacciones rupturistas. Ello no comportaba que existiera descoordinación entre las partes, al contrario, reforzaba el permanente intercambio de información.

El trabajo mancomunado continuaba, pero entendemos ahora que era una colaboración recíproca en la que Cuba podía solicitar -al menos- de los soviéticos ciertos favores.

Para terminar, y como muestra de la extensión en el tiempo de la coordinación Cuba-URSS, hacia 1985 y 1986, con la VIII Conferencia de Harare en el horizonte, el viceministro Mazola decía al ministro Malmierca que el consejero soviético "solicitó... el proyecto de declaración final de Luanda que dice [el embajador Raúl] Roa [Kouri] les prometió; le dije que aún no estaba concluida y que tan pronto la tuviéramos se la entregaríamos" (Comunicación del viceministro, 1985). Y poco después un documento anotaba que el canciller "Malmierca se entrevistó con el Embajador soviético que le entregó un proyecto de modificación al párrafo de la Declaración sobre la moratoria de las pruebas nucleares. Roa tratará de lograr su introducción en la Comisión Política" (“Acta N5”, 1986, p. 4). La URSS, con Perestroika y todo, todavía pretendía intervenir en el rumbo político del MPNA.

\section{Conclusión}

¿Fue Cuba, por todo lo anterior, un satélite soviético? ¿Conservó La Habana la autonomía de su política exterior? ¿Fue la Unión Soviética una potencia hegemónica que impuso sus directrices a Cuba según sus propios y exclusivos intereses? Creemos que Cuba fue dueña de su política exterior en múltiples frentes, pero solo en la medida que sus decisiones no interfirieran 
con los objetivos soviéticos. En ese sentido, no se puede argumentar que Cuba mantuvo su autonomía si el control de Moscú era permanente. En ningún momento Cuba obró en contra de la orientación que recibía, aunque sí se atrevía a solicitar determinadas reconsideraciones por parte de los soviéticos. Para probar que La Habana retuvo su independencia o una parte de ella, no basta con argüir que no consultaba con Moscú cada paso que daba en el No Alineamiento o que discernía acciones de acuerdo a sus propios intereses; debería presentarse, en cambio, un documento que certificara un acto de rebeldía cubano contra los lineamientos soviéticos, o bien una comunicación de la URSS condenando algún exabrupto isleño.

Por cierto, lo expuesto cubre solo una de las facetas de la política exterior cubana y de las relaciones entre Cuba y la URSS. Entendemos, no obstante, que lo ocurrido con el No Alineamiento puede interpretarse como un patrón aplicable a las otras áreas de las relaciones entre la potencia y la isla. Desde un punto de vista más general, este trabajo quiere aportar a la comprensión de la Guerra Fría y, más específicamente, de los vínculos que se establecieron entre las potencias hegemónicas y sus aliados. En ese sentido, forma parte de un conjunto de investigaciones que en los últimos años se ha beneficiado de la apertura de archivos en múltiples puntos neurálgicos de aquel conflicto: la ex Unión Soviética y los otros países socialistas, como la Alemania Democrática; los Estados Unidos, a través de la desclasificación de los documentos de la CIA; lo mismo con China, así como con distintos países del Tercer Mundo, entre ellos, Cuba. Con todo ello se ha reforzado el conocimiento de lo que se conoce como Guerra Fría Global. Es muy probable, en consecuencia, que en un futuro cercano nuevos antecedentes viertan más luz sobre los sucesos analizados aquí.

\section{Referencias}

Allison, Roy (1988). The Soviet Union and The Strategy of Non-Alignment in the Third World. Cambridge: Cambridge University Press.

Castro, Fidel (1979). Discurso pronunciado por el Comandante en Jefe Fidel Castro Ruz, en la sesión inaugural de la VI Conferencia Cumbre del Movimiento de Países No Alineados, celebrada en La Habana, el 3 de septiembre de 1979. Disponible en: http:/www.cuba.cu/gobierno/ discursos/1979/esp/f030979e.html [Consultado el 17 de junio de 2017]. 
D’Estéfano Pisani, Miguel Ángel (2002). Política Exterior de la Revolución Cubana. La Habana: Editorial de Ciencias Sociales.

Domínguez, Jorge I. (1989). To Make a World Safe for Revolution: Cuba's Foreign Policy. Cambridge, MA: Harvard University Press.

Friedman, Jeremy (2015). Shadow Cold War. The sino-soviet competition for the Third World. Chapel Hill, North Carolina: University of North Carolina Press.

Harmer, Tanya (2013). El gobierno de Allende y la Guerra Fría interamericana. Santiago de Chile: Universidad Diego Portales.

Latrèche, Leila (2011). Cuba et l'URSS. 30 ans d'une relation improbable. Paris: L'Harmattan.

Pettavino, Paula J. (1990). "Novel Revolutionary Forms: The Use of Unconventional Diplomacy in Cuba". En G. Fauriol y E. Loser (Eds.), Cuba: The International Dimension (pp. 373-403). New Brunswick: Transaction Publishers.

Riechers, C. Russel (2012). Cuba and the Non-Aligned Movement: Interactions of Pragmatic Idealism. Washington: School of International Service, American University.

Rodríguez, Carlos R. (1982). "Fundamentos estratégicos de la política exterior de Cuba". Casa de las Américas, 22, pp. 11-21.

Rubinstein, Alvin Z. (1988). Moscow's Third World Strategy. New Jersey: Princeton University Press.

Valenta, Jiri (1990). "Cuba in the Soviet Alliance System". En G. Fauriol y E. Loser (Eds.), Cuba: The International Dimension (pp. 3-39). New Brunswick: Transaction Publishers.

\section{Documentos del Archivo del Ministerio de Relaciones Exteriores de Cuba}

"Acta N5", 29 de agosto de 1986. 
“Actividades preparatorias", 1971.

“Al Buró Político", 6 de marzo de 1975.

"Balance de la situación en el MNOAL desde la VI Cumbre hasta la Reunión Ministerial en la India. Presidencia de Cuba", c.1973.

Castro, Fidel. "Discurso ante la $7^{\mathrm{a}}$ Cumbre", 1983.

Castro, Fidel. "Discurso pronunciado en la IV Conferencia Cumbre, celebrada en Argel del 5 al 9 de septiembre de 1973”, 1973.

Comisión de Altos Estudios Políticos, “Apuntes sobre los antecedentes, evolución y las características del Movimiento de No Alineados”, c.1970.

Comunicación del viceministro Mazola al ministro Malmierca, 29 de junio de 1985.

Comunicación dirigida (1) al viceministro de Relaciones Exteriores, 1 de febrero de 1975.

Comunicación dirigida (2) al viceministro de Relaciones Exteriores, 5 de febrero de 1975.

"Discurso del Dr. Raúl Roa García, Ministro de Relaciones Exteriores de la República de Cuba en la IV Reunión de Ministros de Relaciones Exteriores de Países No-Alineados", 1973.

"Discurso del Dr. Raúl Roa, Ministro de Relaciones Exteriores de Cuba, en la Tercera Conferencia de Países No-Alineados", 1970.

Documento sin título $\mathrm{N}^{\circ} 1$, c. 1970.

Documento sin título $\mathrm{N}^{\circ} 2,1976$.

Documento sin título N³, abril de 1983.

Documento sin título N4, c. 1969. 
Documento sin título ํ5, c.1970.

"Evaluación resumida sobre la plenaria del MNOAL", 8 de marzo de 1980.

"III Conferencia de Países No Alineados, Lusaka, Zambia: 6-10 septiembre, 1970", 1970.

"Informe sobre la proyectada Conferencia de Jefes de Estado y de Gobierno de los Países No Alineados”, c.1969.

"Pro memoria", 26 de abril de 1980.

"Problemas focales con relación a la Tercera Conferencia Cumbre de los Países No Alineados", 27 de agosto de 1970.

"Propuestas para concluir la Reunión Plenaria de Embajadores en Nueva York", 9 de junio de 1980.

“Proyecto de directivas para la visita a Afganistán y Pakistán”, c.1980.

"Resumen de las informaciones recibidas en la DOCI en relación con la actividad de los Países No Alineados", c.1978.

Transcripción de entrevista con Marlen Manasov, encargado de negocios de la URSS en Cuba, 7 de agosto de 1976. 